\title{
LA PROTECCIÓN DE LAS FUENTES DE INFORMACIÓN: LA INTEGRACIÓN DEL MODELO ESPAÑOL CON LA JURISPRUDENCIA DEL TEDH
}

\author{
Arancha Moretón Toquero
}

\begin{abstract}
SUMARIO: 1. EL SECRETO PROFESIONAL DE LOS PERIODISTAS: UN DILEMA RECURRENTE. 1.1. Un nuevo supuesto de alegación del secreto profesional de los periodistas: el denominado "caso Tellería». 1.2. El secreto profesional como transfondo constitucional del asunto. 2. EL SECRETO PROFESIONAL DE LOS PERIODISTAS EN ESPAÑA: UN MODELO PROPIO. 2.1. Las modalidades de secreto profesional. El secreto profesional de los periodistas no es una modalidad más de secreto profesional. 2.2. El secreto profesional de los periodistas en el art. 20.1.d) $C E$ : un derecho, no un deber. 2.3. La relación entre el secreto profesional y la libertad de información. 2.4. El secreto profesional y el requisito de la veracidad de la información. 2.5. Otras consecuencias derivadas de una concepción jurídico-constitucional del secreto profesional de los periodistas. 2.5.1. La cuestión de los límites del secreto profesional de los periodistas. 2.5.2. El secreto profesional y la divulgación de información secreta (filtraciones). 3. EL DESARROLLO DEL SECRETO PROFESIONAL DE LOS PERIODISTAS EN LA JURISPRUDENCIA DEL Tribunal Europeo de Derechos Humanos. 4. Bibliografía.
\end{abstract}

\section{EL SECRETO PROFESIONAL DE LOS PERIODISTAS: UN DILEMA RECURRENTE}

La invocación del secreto profesional en el ámbito informativo por lo general se materializa en la contradictoria posibilidad de que el periodista pueda servirse del silencio con la finalidad de sacar a la luz una información relevante de interés general o bien, con la de garantizar que la que in- 
formación que ofrece al público se aproxima al máximo a la «verdad informativa», entendida como relato de hechos apegado a la realidad.

Frente a la publicidad, y en la frontera con la privacidad, se ubica una figura jurídica de perfiles tan poco claros como el secreto profesional que, a día de hoy, transcurridos más de treinta años desde su incorporación a nuestro texto constitucional, continúa siendo una vexata quaestio merecedora de atención desde las más diferentes ópticas pero, sobre todo, desde la jurídica.

Con frecuencia se menciona lo paradójico de que el periodista (cuya profesión consiste en informar) sea protegido para que pueda ocultar la identidad de su fuente. Pero paradójico resulta también, que esta posibilidad de ocultar las fuentes de información, tan esencial para el ejercicio del periodismo (particularmente del periodismo «de investigación») sea, sin embargo, merecedor de un tratamiento jurídico tan confuso y que, particularmente en España, a pesar de que cuenta con reconocimiento constitucional expreso, aún no goce (o padezca-según criterios-) de regulación jurídica que lo desarrolle.

En el ámbito jurídico esta figura ha merecido una atención más bien escasa en España y, hasta hace poco tiempo, también en Europa (lo que contrasta con la numerosa literatura norteamericana); y generalmente la óptica de estudio predominante venía atendiendo a su dimensión profesional y deontológica, ámbito en el que tiene su origen. Pero aún dentro de los estudios específicos de carácter jurídico, también se aprecian importantes diferencias de configuración y alcance, derivadas de la también diversa naturaleza jurídica que se le atribuye a esta figura (como deber, en menor medida como derecho $\mathrm{y}$, en ocasiones, bajo la discutida configuración jurídica del derecho-deber) diferencias que quizá tienen que ver con la inercia de un planteamiento anclado en su dimensión ética, mucho más desarrollada.

Esta escasa atención que el secreto profesional ha merecido como objeto de estudio desde el punto de vista jurídico, contrasta con la relativa frecuencia con que los medios de comunicación se hacen eco de situaciones en las que los profesionales de la información alegan este derecho como medio de defensa en el ámbito (sobre todo) judicial y, en el último tiempo también, en relación con ciertas actuaciones de la autoridad gubernativa.

Efectivamente, es en el ámbito judicial donde con mayor frecuencia desenvuelve sus efectos el secreto profesional aunque, si partimos de la concepción jurídica que ofrece nuestro ordenamiento, y sentado que el periodismo se ejerce, por lo general ${ }^{1}$, en el seno de los medios de comunicación, puede

${ }^{1}$ Esta afirmación merece ser matizada, sobre todo teniendo en cuenta la generalización de Internet como cauce de expresión, pero también de información. En este nuevo espacio, no solo tiene cabida el fenómeno que se ha dado en llamar «periodismo ciudadano» (que es dudoso que se pueda equiparar al periodismo), sino muchas otras actividades informativas en realidad no tan diferentes a las que se desarrollan en los medios escrito o 
desplegar también su eficacia en la relación interna entre particulares, es decir, en la relación laboral o profesional que une al periodista con el medio de comunicación para el que trabaja.

Como es sabido, el secreto se compadece mal con la democracia, a la que es consustancial la transparencia. De hecho el secreto profesional, como excepción a la transparencia, actúa como límite ${ }^{2}$. El secreto es una técnica instrumental ${ }^{3}$ que encuentra su justificación en que sirve para proteger o garantizar otros intereses subyacentes como pueden ser: la protección de un derecho - generalmente la intimidad-, la eficacia de la actuación pública, asegurar un status especial a un colectivo profesional, etc. Este carácter instrumental también es predicable del secreto profesional de los periodistas y se justifica en que la prensa (los profesionales de la información, a quienes se reconoce el secreto profesional) y los medios de comunicación en general, realizan la misión, en palabras del TEDH, de «perro guardián de la democracia».

Pero aún cuando el secreto profesional es, en general, excepción al principio de transparencia, en el caso de los periodistas, por su particular configuración, actúa paradójicamente a su servicio. El secreto de los periodistas encuentra precisamente su justificación en que sirve de vehículo para que informaciones relevantes, de interés público, vean la luz y, por tanto, puedan ser objeto de escrutinio.

No obstante, si bien el recurso al secreto se justifica por los fines que pretende realizar, no es menos cierto que esta técnica se encuentre rodeada de sospecha o recelo pues históricamente el secreto ha operado como un importante instrumento de poder, sustrayendo de control cierta información. Más aún, si (como en el caso de los periodistas) se configura jurídicamente como un derecho fundamental y se deja, por tanto, en manos de su titular su ejercicio.

audiovisual pero en las que en ocasiones falta uno de los sujetos (el medio de comunicación propiamente dicho). Todas estas manifestaciones merecen una consideración separada y específica que excede del objeto del presente trabajo, atendiendo a que no son realidades equiparables entre sí, ni tampoco revisten todas las notas predicables del ejercicio profesional. Estos aspectos los he tratado en «La cláusula de conciencia y el secreto profesional del periodista en Internet», en CorredoIRA, L. y Cotino, L. (coords.), Libertad de expresión e información en Internet. Amenazas y protección de los derechos personales, Centro de Estudios Políticos y Constitucionales, 2013, y en algún extremo también, «El estatuto de los profesionales de la información en la prensa digital», en GAVARA DE Cara, J.C.; de Miguel BÁrcena, J. y Ragone, S. (eds.), El control de los cibermedios, JM Bosch Editor, Barcelona, 2014.

${ }^{2}$ En este sentido, por ejemplo, vid. art. 14, apartado j) de la Ley 19/2013, de 9 de diciembre, de Transparencia, Acceso a la Información Pública y Buen Gobierno (BOE 10 de diciembre de 2013).

${ }^{3}$ El secreto per se carece de valor, salvo que sirva a un fin. 
Por otro lado, también es cierto que el secreto profesional de los informadores puede servir de cobertura a conductas de revelación indebida de información que, por uno u otro motivo, han de permanecer ocultas por tener carácter secreto. Efectivamente, una buena parte de los supuestos en los que los periodistas alegan su secreto profesional tiene que ver con la indagación de la identidad de quien, incumpliendo su deber de custodia o reserva, filtra a un medio de comunicación la información sobre la que existe interés, público o privado, en que permanezca oculta. En estos casos de filtraciones de documentos o informaciones, quien entrega o suministra el documento o la información, es al tiempo la fuente de la noticia de manera que, el secreto profesional se mueve en este caso en una «zona gris», a caballo entre la protección del interés publico en conocer la información, y el interés del titular o depositario de la información en que su identidad permanezca oculta como para evitar las consecuencias del incumplimiento de su deber de secreto.

En este escenario, cuando la reserva de información se encuentra garantizada legalmente, se plantea el dilema de identificar y eventualmente sancionar al autor de la filtración y, al mismo tiempo, garantizar el debido respeto del derecho del periodista a silenciar esta identidad en aras de la libertad de información.

\subsection{Un nuevo supuesto de alegación del secreto profesional de los periodistas: el denominado "caso Tellería»}

El caso así bautizado por la prensa tiene su origen remoto en la publicación en varios diarios de unas informaciones relativas a una presunta trama de corrupción y espionaje a políticos y empresarios.

Uno de los imputados en los hechos objeto de investigación judicial, interpuso denuncia por presunto delito de revelación de informaciones secretas contra varios periodistas y sus respectivos medios de comunicación, sobre la base de que, mientras se estaba tramitando la pieza separada de diligencias previas bajo secreto de sumario (es decir sin que las partes personadas pudieran tener conocimiento de las mismas) simultáneamente varios periódicos estaban publicando una buena parte de la información sumarial reservada, conducta en la que se apreciaba indicio de revelación de secretos.

En la fase de investigación de estos presuntos delitos de revelación del secreto sumarial, los periodistas autores de las noticias publicadas en varios medios de prensa escrita, fueron llamados a declarar sobre dichos hechos, primero en calidad de imputados ${ }^{4}$ por delito de revelación de secretos, y posteriormente, tras acoger parcialmente en este extremo el recurso del Ministerio Fiscal, como testigos de la causa ${ }^{5}$.

${ }^{4} C f r$. Auto de 24 de agosto de 2010, del Juzgado de Instrucción $\mathrm{n}^{\mathrm{0}} 2$ de Vitoria.

${ }^{5}$ Cfr. Auto de 27 de septiembre de 2010, del Juzgado de Instrucción nº 2 de Vitoria. 
Todos estos profesionales, acogiéndose a su derecho a no revelar sus fuentes de información, se negaron a contestar a las preguntas referentes al origen de la información, manifestando algunos de ellos que, incluso conocían que lo que publicaban se encontraba bajo secreto del sumario.

Sin perjuicio de otras cuestiones relevantes, y en lo que afecta al secreto profesional, en varias de las resoluciones recaídas en este proceso se contiene no solo (y como excurso) una referencia a la ausencia de regulación y a la complejidad de determinación de lo que sea el secreto profesional de los periodistas, sino una inevitable remisión a los criterios establecidos por el TEDH en varias de sus sentencias, sin referencia al modelo español constitucionalmente establecido, a falta de regulación legal.

En este asunto se plantean varias cuestiones que, desde la óptica del secreto periodístico merecen especial atención: una primera cuestión de carácter sustantivo, como es la de si los periodistas pueden ser o no autores (directos o cooperadores necesarios) del delito de revelación de actuaciones judiciales secretas (tipificado en el art. $466 \mathrm{CP}$ ) que conocemos como «filtraciones» informativas; y otra cuestión de orden procesal, pero también y, sobre todo, con un fuerte transfondo constitucional (que es el que aquí consideramos): la cuestión de la eficacia y alcance de la alegación por los periodistas de su secreto profesional ante la autoridad judicial para no revelar las fuentes de las informaciones publicadas. En este último sentido, también se suscita la necesidad de resolver la colisión entre el derecho al sigilo y el deber de justificar la veracidad de la información, así como la eventual posibilidad de excluir la operatividad del secreto profesional cuando estamos ante la publicación de datos secretos.

\subsection{El secreto profesional como transfondo constitucional del asunto}

Tanto la cuestión de la antijuricidad y la justificación de la conducta imputada a los periodistas en este caso, como la relativa a la alegación del secreto profesional para no reportar a la autoridad judicial los datos solicitados, reavivan una vez más la cuestión de la delimitación de las prerrogativas de las que gozan los profesionales de la información ${ }^{6}$ en defensa del ejercicio de su propia libertad profesional, en primer término, pero sobre todo, como instrumento de la libertad de información «del público al público», en general.

En definitiva, se trata de ponderar bienes jurídicos de tanta relevancia como el interés en la eficacia de la investigación del delito, o el interés del correcto ejercicio de la administración de justicia, la efectividad de la protec-

${ }^{6}$ No obstante esta es una cuestión debatida por una parte de la doctrina y por alguna jurisprudencia estadounidense, partidaria de extender esta prerrogativa a los informadores no profesionales, cuestión que se suscita, sobre todo, atendiendo al ejercicio de la libertad de información en Internet. 
ción de las informaciones declaradas secretas frente a la filtración, o la libertad de información en su doble vertiente de dar y recibir información veraz.

Volviendo al caso expuesto que hemos tomado como hilo conductor de este trabajo, y tal como se relata en una de las resoluciones, la defensa de los periodistas frente a la imputación del delito de revelación de informaciones sumariales declaradas secretas, se fundamenta en la aplicación de la eximente de ejercicio de un deber del art. 20.7 CP en relación con el art. 20.1.d) de la Constitución española, que garantiza el derecho a difundir información veraz reconociendo el secreto profesional.

Este motivo, que finalmente encuentra acogida, merece una consideración detallada por parte del órgano judicial, que hace bascular su respuesta en la libertad de información y en el secreto profesional, en el que hace especial hincapié, anticipándose de algún modo a la solución finalmente adoptada en el auto de sobreseimiento de la causa ${ }^{7}$.

Los argumentos expuestos en el segundo auto, quizá deberían haberse centrado no obstante, en la apreciación de la concurrencia de los parámetros constitucionales del ejercicio de la libertad de información protegida por el art. 20.1.d) CE, o en la profesionalidad de sus agentes para encontrar amparo en las causas de justificación segunda y tercera del art. 20.7 CP (ejercicio de un derecho u oficio), sin embargo se polarizan en la consideración del secreto profesional alegado, recalcando la indeterminación de su consideración jurídica.

Esta indeterminación se pone de manifiesto en las resoluciones citadas en las que, con razón, se menciona expresamente que se trata de «una cuestión compleja que no está resuelta de modo unánime», sobre todo, en lo relativo a la naturaleza del secreto profesional, su eficacia y extensión, que merecen un análisis más detallado y, a falta de jurisprudencia y regulación legal, una construcción jurídica que pueda ofrecer una mayor seguridad. La falta de unanimidad, sin embargo, generalmente suele venir motivada por la consideración de esta figura desde su dimensión de deber deontológico, y no tanto, de su dimensión jurídica, si bien en este extremo también hemos señalado algunas de las posiciones divergentes.

\section{EL SECRETO PROFESIONAL DE LOS PERIODISTAS EN ESPAÑA: UN MODELO PROPIO}

\subsection{Las modalidades de secreto profesional. El secreto profesional} de los periodistas no es una modalidad más de secreto profesional

Nuestra Constitución contiene una diversidad de menciones, directas e indirectas al secreto, si bien, las que se refieren al que se desenvuelve en el

${ }^{7}$ Cfr. Auto de 15 de septiembre de 2011, del Juzgado de Instrucción n. ${ }^{\circ} 2$ de Vitoria. 
ámbito profesional, se contienen en los artículos 20.1. d) CE, relativo al «secreto profesional de los periodistas», y en el el art. $24 \mathrm{CE}$, que contiene una referencia genérica al «secreto profesional».

La doble mención constitucional obliga a plantear la cuestión del significado y funcionalidad de cada una de ellas, así como la posibilidad de conexión entre ambas.

El secreto profesional, antes que en el ámbito del periodismo tuvo reconocimiento en profesiones diferentes, singularmente las profesiones liberales (medicina y abogacía) y, mutatis mutandis, en el ámbito religioso (sigillum confessionis). En cada uno de estos ámbitos la protección del secreto tiene un fundamento diferente: bien la protección de la intimidad, el mantenimiento de la confianza de quien suministra la información, o también el pincipio alterum non laedere... Pese a todo, se puede afirmar que existen algunas características comunes, por diferentes que sean los ámbitos en los que se acoge, como son: su configuración con la doble vertiente de derecho-deber, la responsabilidad derivada de su incumplimiento y la falta de desarrollo legislativo.

Es preciso considerar, en una primera aproximación, que las dos menciones constitucionales al secreto profesional se desarrollan en ámbitos bien distintos: mientras que el art. $24 \mathrm{CE}$ recoge las llamadas «garantías procesales» (referidas principalmente al proceso penal), el art. $20 \mathrm{CE}$ regula las «libertades informativas» (a comunicar o recibir libremente información veraz por cualquier medio de difusión en el ejercicio de las cuales, la ley regulará el derecho al secreto profesional). Es decir, mientras que el contenido del art. $20 \mathrm{CE}$ tiene un carácter material, el art. $24 \mathrm{CE}$ se refiere fundamentalmente al ámbito procesal y presupone, además, una razón o motivo previo a la exención («por razón de», dice expresamente): la existencia de un deber, en este caso, de carácter profesional.

\subsection{El secreto profesional de los periodistas en el art. 20.1.d) CE:} un derecho, no un deber

En el caso expuesto, los periodistas apelaron para fundamentar la exención de responsabilidad por su actuación en relación con las presuntas filtraciones del contenido del sumario, a las causas previstas en el n. ${ }^{\circ} 7 \mathrm{del}$ art. $20 \mathrm{CP}$.

Las causas de exención de responsabilidad previstas en este apartado 7 , tienen la naturaleza de causas de justificación de la conducta penalmente relevante fundamentada ${ }^{8}$ no solo en el carácter de ultima ratio propia del Derecho Penal sino, sobre todo, en la evitación de las contradicciones que pudie-

8 Vid. SÁnchez García de Paz, M. I., «Art. 20.7», en Gómez Tomillo, M. (coord.), Comentarios al Código Penal, Ed. Lex Nova, 2010. 
ran eventualmente producirse entre la norma penal y la conducta de quien actúa en el ejercicio legítimo de un derecho, una profesión o un deber amparado por la ley.

En este sentido, la apelación por la defensa de los periodistas al art. 20.7 $\mathrm{CP}$ debe circunscribirse al ejercicio de un derecho (y un derecho fundamental) como es la libertad de información, o al ejercicio de una profesión, como es la periodística que, llevada a cabo dentro de los parámetros que la Constitución establece (y esto entra en el campo valorativo) podría servir de justificación a la conducta. Ello sin perjuicio de que, como garantía de esa libertad, los sujetos que profesionalmente la ejercen, los periodistas, puedan además acogerse a la protección que les brinda su secreto profesional para oponerse a medidas de investigación judicial (o policial, en su caso) como el interrogatorio, el registro o el secuestro de ciertos materiales, con la finalidad de preservar la identidad de sus fuentes.

Sin entrar a valorar la pertinencia o no de la concreta causa de justificación alegada y la posibilidad de otras opciones, dado que todas ellas se encajan en el art. 20.7 CP (y tuvo acogida favorable en el fallo), las argumentaciones contenidas en estas resoluciones tienen un gran interés, no solo por el esfuerzo argumentativo de la resolución sino también y, sobre todo, porque invitan a una reflexión más profunda acerca de las instituciones y derechos en juego.

El art. 20.1 CE, al tiempo que consagra el derecho a dar y recibir información veraz reconoce y remite al legislador el reconocimiento del derecho a la cláusula de conciencia y al secreto profesional de los periodistas «en el ejercicio» de esas libertades.

Esta previsión constitucional parece remitir, prima facie, a una institución clásica del periodismo escrito, directamente conectada con la libertad de información y con el comportamiento ético del periodista: el respeto del compromiso contraído por el periodista con su fuente para mantener oculta su identidad y con ello salvaguardarla de posibles represalias o simplemente, para respetar su deseo de no ser identificado.

Sin embargo, este concepto de secreto profesional, si bien sigue siendo válido, desde un punto de vista estrictamente jurídico queda en gran medida desplazado por la necesidad de una construcción conforme con la previsión constitucional que, solo en apariencia, encaja con la concepción «tradicional» indicada, lo que, desde mi punto de vista.

A este respecto, el secreto periodístico considerado en su concepción «tradicional», como deber ético, no sería apto (y esta es una cuestión pacífica en la doctrina y jurisprudencia) para justificar una conducta penal como la revelación de información protegida por el secreto del sumario, pues el precepto indicado se refiere a un deber jurídico, impuesto por la norma, y no al deber que cae en el campo de la ética, la moral o, en su caso, el ámbito religioso. 
En el supuesto de que el secreto profesional fuera la causa justificativa9, solo el secreto profesional, con valor jurídico, concebido como derecho, podría justificar esa conducta.

Pero, en realidad, la justificación de la conducta se encuentra, no tanto en el cumplimiento de un deber (el secreto profesional, que como deber queda en el ámbito de la ética), sino en el ejercicio (y, en este caso, ejercicio profesional) de la libertad de información del periodista dentro de los parámetros constitucionales, con independencia de que en garantía de esta libertad, la propia Constitución también proteja el derecho al secreto profesional, es decir, el derecho a no revelar a terceros la identidad de las fuentes de información

En relación con esta cuestión, si bien es cierto que la Constitución consagra en el art. 20.1.d) el secreto profesional pero ni define ni delimita su contenido, los amplios márgenes de incertidumbre que ello suscita vienen motivados seguramente por la inercia del que ya he destacado como «concepto tradicional», anclado en el campo de la deontología profesional (que concibe el secreto como un deber) así como en la ausencia de un modelo jurídicoconstitucional de secreto profesional que encaje en el art. $20 \mathrm{CE}$, al servicio no de la protección individual del periodista, sino como garantía misma de la libertad de información.

En este sentido, por su cercanía, puede ser aplicable al secreto profesional del periodista la afirmación contenida en la STC 199/1999, de 8 de noviembre, referida directamente a la cláusula de conciencia: la de que «el reconocimiento de la cláusula de conciencia al profesional de la comunicación en el ejercicio de su libertad de información no puede entenderse exclusivamente como un derecho particular de aquél; sino, al tiempo, como garantía de que a su través se preserva igualmente la satisfacción del carácter objetivo de dicha libertad, de su papel como pieza básica en el sistema democrático y de su finalidad como derecho a transmitir y recibir una información libre y plural.»

\subsection{La relación entre el secreto profesional y la libertad de información}

Sentada la configuración del secreto profesional en nuestro ordenamiento jurídico-constitucional como un derecho, queda pendiente de precisar la razón de su «fundamentalidad» así como su relación con la libertad de información, pues es ahí donde encuentra su verdadero sentido y justifica la superación de una concepción puramente ética.

${ }^{9}$ En este caso, la apelación al ejercicio legítimo de la libertad de información quizá sería suficiente para fundamentar la justificación de la conducta. La apelación al secreto profesional, íntimamente ligada al ejercicio profesional de la libertad de información por estos profesionales, encuentra (aunque no exclusivamente) un campo de acción abonado en la práctica procesal, como medio de defensa, sin perjuicio de su naturaleza sustantiva como derecho fundamental. 
La ubicación «geográfica» del secreto profesional en el art. $20 \mathrm{CE}$, y su reconocimiento «en ejercicio» de las libertades informativas clarifica su naturaleza de derecho fundamental, si bien está por determinar su relación con dichas libertades. Como bien señala FernÁndEZ-MiRANDA, «una adecuada interpretación del artículo 20.1.d) CE exige, una vez determinado cuál es el bien jurídico protegido, analizar la exacta posición que ocupa en el ordenamiento jurídico, porque el alcance de un derecho instrumental, como es el derecho al secreto profesional, está en íntima dependencia del significado jurídico de los derechos sustantivos que garantiza: los derechos informativos» ${ }^{10}$.

Efectivamente, a diferencia del secreto profesional reconocido en el ámbito de otras profesiones, la fundamentación del secreto del periodista no se encuentra en «la protección de la intimidad ni en un deber jurídico de sigilo de la fuente, sino en el derecho a la información como derecho cuya titularidad corresponde a la sociedad, siendo el periodista un mero pero imprescindible intermediario» ${ }^{11}$.

La importancia de la función que desarrollan los profesionales de la información para la configuración de una opinión pública libre ha determinado, sin duda, la constitucionalización del secreto periodístico de forma diferenciada del secreto profesional que opera en relación con otras profesiones.

En el caso de los periodistas, el derecho a ocultar la identidad de la fuente se dirige a proteger, en última instancia, la opinión pública, intentando evitar la manipulación y facilitando el flujo informativo así como su origen plural lo que, en última instancia redunda en una mayor riqueza y objetividad informativa.

Así concebido, los informadores gozan de un derecho no tanto en beneficio propio personal sino, en todo caso, de su profesionalidad en la medida en que, en última instancia, y dado que son intermediarios naturales en el proceso comunicativo, este beneficio se tornará en un beneficio colectivo o social. Una de las manifestaciones de este derecho (aunque no la única) es la de no revelar cierta información a terceros, particulares o poderes públicos y entre ellos, singularmente, a la autoridad judicial.

Por tanto, la previsión del secreto periodístico como derecho, independiente de la mención del art. $24 \mathrm{CE}$, permite afirmar por un lado, que su naturaleza no tiene solo carácter procesal y, por otro, que tiene un contenido propio que trasciende al proceso.

Esta autonomía e identidad propia del secreto profesional de los periodistas como derecho fundamental, se predica también de la libertad de información, pese a la intensidad de los lazos que les unen. De esta forma, la delimi-

${ }^{10}$ Fernández-Miranda Campoamor, A., El secreto profesional de los informadores, Tecnos, Madrid, 1990, p. 104.

${ }^{11}$ Ibídem. 
tación de los distintos elementos que configuran el secreto profesional no necesariamente habrán de coincidir con la libertad informativa aunque esta le sirva de presupuesto.

Así las cosas, podríamos decir que la Constitución «inaugura» una configuración del secreto profesional como derecho y como medio de defensa de los profesionales de la información, pero también como una figura independiente de los intereses de la fuente.

Se trata de un derecho que hipotéticamente, aún cuando no existiera su reconocimiento constitucional expreso, bien podría haberse deducido del art. 20.1 d) CE (de manera similar a como opera el TEDH en relación con el Convenio Europeo de Derechos Humanos) como una garantía del pluralismo o del acceso a la pluralidad de fuentes de información, al servicio de la verdad y la objetividad informativa pues, como señala Ignacio VILLAVERDE, «controlar las fuentes es una forma sibilina de manipulación informativa» ${ }^{12}$.

A diferencia de lo que ocurre en el ordenamiento español, que prevé expresamente el secreto periodístico, en el ámbito europeo no se encuentra expresamente mencionado ni en la Declaración Universal de Derechos Huma${ }_{n o s}{ }^{13}$, ni en el Pacto Internacional de Derechos Civiles y Politicos ${ }^{14}$. Tampoco se realiza mención ni en la Carta de Derechos Fundamentales de la Unión Europea ${ }^{15}$ ni en el Convenio Europeo de Derechos Humanos ${ }^{16}$, donde se consagra la libertad de expresión e información de modo general, pero sin referencia expresa a su ejercicio por los profesionales de la información y las especialidades que esto comporta.

12 Villaverde MenÉndez, I., El secreto profesional de los periodistas. Informe de su régimen jurídico en España, inédito, 1997.

13 DUDH de las Naciones Unidas, de 10 de diciembre de 1948.

14 PIDCP, de 19 de diciembre de 1966 (ratificado por España el 13 de abril de 1977).

${ }^{15}$ CDFUE, de 18 de diciembre de 2000 (Diario Oficial $n .{ }^{\circ} \mathrm{C} 364$ de 18/12/2000 p. 0001 c 0022).

$16 \mathrm{El} C E D H$, de 4 de noviembre de 1950 (ratificado por España el 26 de septiembre de 1979) no se refiere al secreto profesional. En relación con la libertad de expresión, su artículo 10 dispone: «Artículo 10. Libertad de expresión. 1. Toda persona tiene derecho a la libertad de expresión. Este derecho comprende la libertad de opinión y la libertad de recibir o de comunicar informaciones o ideas, sin que pueda haber injerencia de autoridades públicas y sin consideración de fronteras. El presente artículo no impide que los Estados sometan a las empresas de radiodifusión, de cinematografia o de televisión, a un régimen de autorización previa. 2. El ejercicio de estas libertades, que entrañan deberes y responsabilidades, podrá ser sometido a ciertas formalidades, condiciones, restricciones o sanciones previstas por la ley, que constituyan medidas necesarias, en una sociedad democrática, para la seguridad nacional, la integridad territorial o la seguridad pública, la defensa del orden y la prevención del delito, la protección de la saludo de la moral, la protección de la reputación o de los derechos ajenos, para impedir la divulgación de informaciones confidenciales o para garantizar la autoridad y la imparcialidad del poder judicial». 
No obstante, la falta de reconocimiento explícito en el Convenio Europeo de Derechos Humanos no ha sido obstáculo para que el TEDH, en su jurisprudencia, lo haya deducido del artículo 10 del Convenio ${ }^{17}$ considerando que se encuentra implícitamente contenido en el mismo y que, por tanto, la libertad de recibir información comporta la protección absoluta de las fuentes de los periodistas.

Los ya numerosos pronunciamientos del Tribunal Europeo han tenido, por otra parte, una influencia innegable en el desarrollo normativo que se ha producido, con especial intensidad, sobre todo en esta última década, en la mayor parte de los países miembros, anticipándose al legislador español a pesar del mandato constitucional. Esto ha ocasionado que a falta de regulación, los criterios y la construcción del TEDH sean un referente para integrar el contenido del art. 20.1.d) CE.

El reconocimiento constitucional del secreto profesional de los periodistas fue pionero en España pero paradójicamente, a falta de regulación legal, en la actualidad el modelo se ha visto superado por aquellos países que, aunque inicialmente carecían, incluso, de reconocimiento jurídico de esta figura, ya han iniciado un proceso legislativo intenso sobre la materia, incorporando la jurisprudencia del TEDH al más alto nivel, lo que, en nuestro caso, a falta de ley de desarrollo, tiene lugar por la vía del art. $10 \mathrm{CE}$.

La previsión constitucional española, en su momento sin parangón en los países de nuestro entorno, se anticipó y desmarcó de la regulación existente acogiendo una concepción del secreto profesional anclada en su aspecto ético o deontológico. Sin embargo, la evolución de la jurisprudencia del TEDH ha venido a adoptar una configuración más cercana a la nuestra que a la de otros países europeos, de forma que encuentra hoy en nuestro ordenamiento una mejor posibilidad de acomodo que en esos otros ordenamientos, que han precisado un cambio profundo por vía legislativa pero, sobre todo, jurisprudencial, para colocarse en la línea de la doctrina del Tribunal de Estrasburgo y reconocer de manera efectiva este secreto profesional. En definitiva, en nuestro país, el reconocimiento constitucional paradójicamente ha actuado, en cierta medida, como freno al desarrollo normativo de esta figura.

\subsection{El secreto profesional y el requisito de la veracidad de la información}

La cuestión de la compatibilidad entre el secreto profesional y el cumplimiento del requisito de la veracidad de la información es una cuestión a la

${ }_{17}$ Entre las sentencias del Tribunal Europeo que se ocupan del secreto profesional se encuentran, por todas: Casos Roemen y Schmidtcs. Luxemburgo, recurso núm. 51772/99, Sentencia del TEDH de 25 de febrero de 2003, caso Damman vs. Suiza, Sentencia del TEDH de 25 de abril de 2006, y más recientemente, caso Sanoma vs. Holanda, recurso núm. 38224/03, Sentencia del TEDH de 14 de septiembre de 2010. 
que se hace referencia específica en el Auto de sobreseimiento provisional de este caso.

El secreto profesional, como derecho, se encuentra reconocido junto con la cláusula de conciencia «en el ejercicio de estas libertades», dice la CE, que no son otras que las libertades de «comunicar o recibir libremente información», mencionadas co anterioridad en ese mismo apartado. Por tanto, es en este marco de la libertad de información (y no de expresión) donde el secreto profesional tiene cabida y despliega sus efectos actuando como presupuesto de ejercicio de este derecho.

La posibilidad de ocultación de información hay que entenderla referida a las fuentes de la información no lógicamente, a la expresión, que es un acto puramente subjetivo o valorativo cuyo origen está en su autor y no requiere de la veracidad. Ello sin perjuicio de que la expresión tenga como origen remoto una información o que, en la práctica, efectivamente información y expresión se muestren entremezcladas y no sea posible deslindar con precisión quirúrgica las fronteras entre una y otra (en cuyo caso habrá que acudir, como ya es criterio asentado, al elemento preponderante del mensaje).

Dicho esto, y sentado que el secreto profesional opera sobre el presupuesto de un acto de información de interés general y relevancia pública, habría que afrontar, de manera particular, la cuestión de la veracidad como atributo de la información merecedora de la protección constitucional, puesto que la libertad de información actúa como presupuesto de ejercicio del secreto profesional, y la relación entre ambos se articula fundamentalmente a través del requisito de la veracidad.

En su acepción subjetiva, como parámetro de actuación diligente del informador, la veracidad, requisito de la información constitucionalmente protegida, no necesariamente coincide con la forzosa identificación de las fuentes. Efectivamente, en algunas ocasiones la vía más rápida y segura de cumplir con el requisito constitucional sea la identificación del confidente, pero precisamente el reconocimiento del derecho a guardar el secreto faculta para ocultar esta información y ofrecer otros medios de prueba que, al menos indiciariamente, muestren que se hizo lo oportuno y exigible para contrastar la información.

Ciertamente el periodista que quiere ocultar sus fuentes, antes de ofrecer la información, se guardará de contar con otros medios distintos con los que cumplir con el requisito de la veracidad o, en otro caso, asumirá las consecuencias que pudieran derivarse del incumplimiento de este requisito (que no debe confundirse con la no acogida del secreto profesional).

Una cabal concepción del funcionamiento de esta figura debería, por tanto, contribuir a minorar la desconfianza que frecuentemente le rodea, dificultando que se pueda afirmar a priori que per se, el secreto profesional fomente la difusión de chismes o rumores; antes bien, su correcto acogimiento no solo exige su alegación en el ámbito de la libertad de información que cumple con los 
parámetros que le hacen merecedora de protección constitucional ${ }^{18}$, sino que tampoco exonera al profesional de cumplir con el requisito previo de la veracidad y demostrar su diligencia a través de otros medios a su alcance.

Esto quiere decir, en definitiva, que lo mismo que no se protege constitucionalmente la información a ultranza, tampoco se protege de forma ilimitada el secreto profesional, pues no está previsto que sirva a la propagación de rumores o falsedades garantizando la impunidad del periodista ${ }^{19}$, o como vehículo o instrumento para la manipulación informativa por parte de la fuente.

De esta forma, no cabe alegar con eficacia el secreto profesional para amparar, por ejemplo, al periodista que informa sobre asuntos banales, chismes, o asuntos puramente privados de una persona, sin trascendencia informativa. La eventual negativa a desvelar su fuente podría tener otra justificación como la protección de la intimidad o, simplemente, la propia protección del periodista o del medio para el que trabaja, o la exclusividad de su información pero, en cualquier caso, esta finalidad cae fuera de la protección que brinda el secreto profesional y, por tanto, no puede beneficiarle.

No estamos, por tanto, ante un límite sustancial o material del secreto profesional, sino ante la definición misma de su contenido.

En definitiva, no se trata de una colisión entre un derecho (el secreto profesional) y un deber (la veracidad) sino, más bien, ante la necesidad de constatar que, quien alega el secreto profesional lo haga dentro de los parámetros constitucionales: en el ejercicio constitucional de la libertad de información (y por lo tanto, con respeto a la veracidad informativa) que actuará como presupuesto.

\subsection{Otras consecuencias derivadas de una concepción jurídico-constitucional del secreto profesional de los periodistas}

El reconocimiento deserto profesional de los periodistas en el art. $20 \mathrm{CE}$ no solo disipa las dudas acerca de su existencia como institución de carácter

${ }_{18}$ La jurisprudencia constitucional ha declarado repetidamente (por todas, la STC 199/1999 de 8 de noviembre) que la libertad de información reconocida en el art. 20.1 d) $\mathrm{CE}$ se refiere a la transmisión de manera veraz de hechos noticiables, de interés general y relevancia pública (vid. también, SSTC 105/1983, de 23 de noviembre, FJ 11º; y 6/1988, de 21 de enero, F.J. $5^{\circ}$ ), de manera que, fuera de esos límites, la información no goza de la protección constitucional.

19 Sirva, por todas, la STC 6/1996, de 16 de enero, en la que se lee (FJ 4..$^{\circ}$ ): «no es ocioso recordar que este Tribunal ha repetido en numerosas ocasiones que el contenido constitucional del artículo 20.1, d) CE consiste en suministrar información sobre hechos que se pretenden ciertos, por lo que la protección constitucional de su reconocimiento se extiende únicamente a la información veraz (entre muchas otras, SSTC 6/1988, 20/1990, 105/1990, y 133/1995).De este modo, determinar qué debe entenderse por veracidad es de especial importancia para establecer si la conducta del informador responde al ejercicio de un derecho constitucional o si su actuación se sitúa fuera del campo de protección del mismo». 
jurídico sino que le atribuye la fuerza y garantías propias de su naturaleza constitucional, y más aún, de derecho fundamental, en orden a su protección y eficacia.

La de la eficacia del secreto profesional es, sin duda, una de las escasas cuestiones sobre las que existe acuerdo en la doctrina española ${ }^{20}$, que viene admitiendo pacíficamente su operatividad, de modo absoluto, en lo tocante a su alegación frente a las personas (físicas o jurídicas) e instituciones de carácter privado $\mathrm{y}$, con algunas limitaciones y diferencias de opinión, en relación con las personas de carácter jurídico público.

$\mathrm{Y}$ es que las situaciones en las que eventualmente el periodista se puede encontrar interpelado acerca de la identidad de sus fuentes informativas, puede ser de lo más variado: desde el interrogatorio judicial, al requerimiento de una comisión de investigación en sede parlamentaria, por ejemplo o, de forma más inmediata, el requerimiento formal por parte de sus superiores, incluido el director del medio al que pertenece. Ello sn contar que, además de esa vía directa, existen otras de carácter indirecto a través de las cuales también se puede violentar el secreto profesional, como son, por ejemplo, el registro del domicilio, despacho o lugar de trabajo, enseres, materiales y notas, etc., (supuestos tenidos en cuenta en varias sentencias del TEDH).

\subsubsection{La cuestión de los límites del secreto profesional de los periodistas}

El secreto profesional de los periodistas, se desenvuelve en un «hábitat propio», que ya he descrito, fuera del cual es difícil afirmar su pervivencia. En efecto, fuera de ese ámbito natural, aparece una «zona gris» en la que el secreto periodístico coexiste con otros intereses, también protegidos jurídicamente que, por tanto, han de ser tomados en consideración y que, en tal medida, pueden poner en discusión, si no la existencia, sí la eficacia del secreto profesional en algunos supuestos.

En el «caso Tellería», como justificación de la limitación del secreto profesional como consecuencia de las diligencias acordadas por el juez acordando la declaración de los profesionales, se dice que «la injerencia en el secreto profesional debe ser en todo caso necesaria y proporcional en relación con el interés social relevante en la noticia, la veracidad, la posibilidad de obtenerla por otros medios, etc.». Se admite que el secreto profesional pueda ser limitado por un interés legítimo relevante que deberá ser valorado en cada caso concreto.

${ }^{20}$ En este mismo sentido, Fernández-Miranda Campoamor, A., El secreto profesional de los informadores, op.cit., p. 148; CARRILlO, M., La cláusula de conciencia y el secreto profesional de los periodistas, Generalitat de Catalunya, Centre d'Investigació de la Comunicació, Cuadernos Civitas, Civitas, Madrid, 1993, pp.176 y 205 a 206. 
Efectivamente, como bien señala la resolución, las limitaciones han de ser entendidas con carácter restrictivo, pero esta afirmación es una consecuencia de la doctrina general de los derechos fundamentales que no puede considerarse de manera aislada: solo una concepción jurídica del secreto profesional como derecho fundamental superadora de ese otro concepto «clásico» al que me he referido, permite aplicar el criterio general favorable a su expansión y consecuentemente restrictivo de la interpretación de sus límites.

\subsubsection{El secreto profesional y la divulgación de información secreta (filtraciones)}

Otra de las cuestiones que se plantean en la causa, es la relativa a la posibilidad o no de invocar el secreto profesional en relación con la información declarada secreta. Efectivamente en el auto de sobreseimiento se acoge el criterio jurisprudencial del TEDH para admitir la posibilidad de amparo del profesional, aún cuando se trate de divulgación de información declarada confidencial o reservada. De esta forma, se diferencia lo que son los límites de la libertad de información de los contornos del secreto profesional de los periodistas, que por su individualidad, no tiene por qué coincidir.

En la apreciación de la extensión de la libertad de información, nuestra jurisprudencia constitucional ${ }^{21}$ acude a la doctrina de la preeminencia de la libertad de información como herramienta esencial en el sistema democrático para afirmar su preferencia sobre otros derechos fundamentales como el honor, la intimidad o la propia imagen, eso sí, siempre que la información sea veraz y resulte de interés público.

En el lado opuesto, entre los límites específicos que dejarían sin efecto el secreto profesional, se podrían citar, por ejemplo, la evitación de un delito o de un daño a las personas (en cuyo caso, el periodista ni siquiera tendría un deber moral de callar sino, antes bien, mantendría su deber de denuncia), el conocimiento de la falsa imputación de un delito, la mala fe del periodista o su participación delictiva del en la obtención y difusión de la información. Otros bienes jurídicos que podrían ser invocados para hacer decaer el secreto profesional (reconocidos en la legislación comparada) son, por ejemplo, la seguridad colectiva, la defensa nacional, o la estabilidad económica.

Estas circunstancias limitadoras, como hemos reiterado, han de establecerse e interpretarse con carácter restrictivo, no solo por tratarse de un derecho fundamental sino, por su marcada dimensión institucional, y han de contar con todas las garantías, dentro de las cuales podemos citar la motivación de la medida limitadora. En este sentido, podría afirmarse que el secreto profesional de los periodista opera, a su vez, como límite a las medidas de

${ }^{21}$ Por todas, SSTC 46/2002, de 25 de febrero de 2002; y 129/2009, de 1 de junio de 2009. 
investigación judicial (y, desde luego, policial) separando con ello la función periodística de la investigadora (ya sea policial o judicial).

En el caso particular examinado, en el ámbito de la investigación de un delito de revelación de secretos (de secreto sumarial), la juzgadora hubo de apreciar la colisión entre el interés público en la persecución del delito y el derecho a la ocultación de las fuentes que, en tanto derecho fundamental íntimamente ligado a la libertad de información, goza de una posición preeminente. Precisamente con apoyo en la doctrina constitucional que consagra la preeminencia del derecho a transmitir información (cita a este respecto las SSTC 46/2002; y 129/2009) $\mathrm{y}$ atendiendo a que, en cualquier caso esta preeminencia no es ilimitada, sino que, en todo caso, la información debe ser veraz y resultar de interés publico, valora que no concurren en el supuesto circunstancia de carácter "suficientemente vital y grave" como para que los periodistas vengan obligados a revelar la fuente, finalmente acuerda el sobreseimiento de la causa.

Aunque no se plantea abiertamente, sí cabría valorar la posición procesal de los periodistas en la causa, y también el efecto que eventualmente esto produce en relación con el secreto profesional, pues parece que esta es la razón que subyace en la motivación de la resolución del recurso del Ministerio Público. Con carácter general se aprecia la imposibilidad de alegación del secreto profesional por parte del periodista imputado reduciendo por tanto su ámbito de acción a los supuestos en que el periodista es llamado a declarar en calidad de testigo. Encuentro que esta opción resulta en exceso restrictiva y que obvia un dato fundamental como es la de que, en el caso del periodista imputado, la posibilidad de alegar el silencio es doble: de una parte, puede alegarlo en ejercicio de una prerrogativa profesional pero también, en el ejercicio de su derecho de defensa.

Por tanto, estimo que no se puede afirmar con rotundidad que el secreto profesional no opere en estos casos, sino que en el silencio del periodista se pueden solapar dos facultades de silencio, difíciles de deslindar: el ejercicio del secreto profesional y su derecho, también fundamental, a no declarar.

Por otra parte, no se puede perder de vista que encontramos en el ámbito de un proceso judicial en fase de investigación, y es aquí donde con más frecuencia se produce el cuestionamiento de la eficacia del secreto profesional y donde la necesidad de los límites aparece más patente ${ }^{22}$.

${ }^{22}$ En una de sus facetas, el secreto tiene una naturaleza dinámica, y defensiva «frente a» quien quiere conocer la identidad de quien suministra la información. De esta forma, el secreto profesional protege una parcela de información que se mantiene fuera del conocimiento de terceros, bien sean lectores, espectadores, o bien, poderes públicos.

Ahora bien, siendo esta su faceta más visible, el secreto profesional, en sentido amplio, supera esta dimensión protegiendo (como de hecho hace el TEDH en su jurisprudencia) la función, los materiales y lugares de trabajo, aún cuando no exista un requerimiento de información determinado, dirigido contra el periodista. 
En cualquier caso, en su valoración, a falta de criterio legal, habría de tener en cuenta, entre otros, los siguientes aspectos:

- Por un lado, la naturaleza de derecho fundamental y la dimensión objetiva del secreto profesional como garantía de la libertad informativa.

- De otro, el paralelismo entre la actividad investigadora de la prensa y del órgano judicial, así como las diferentes herramientas y fines que cada uno de ellos persigue y que, no solo no tienen por qué que ser coincidentes, sino que se ha de vencer la tentación de convertir (como reiteradamente se ha señalado por la doctrina) a los periodistas en confidentes de la policía o de la autoridad judicial.

- En tercer lugar, al menos, tomar en consideración que, precisamente la función informativa consiste en trasladar al público información veraz de relevancia social y, el deber de custodiar la información y la restricción de su publicidad es un deber que recae, en la propia Administración de Justicia ${ }^{23}$.

- Finalmente, como acertadamente pone de relieve Pilar OTERO, «de la existencia de ese deber o este derecho (de secreto profesional) no se deduce, automáticamente, el nacimiento de ninguna exoneración, como la dispensa del deber de declarar o de denunciar en el proceso penal $»^{24}$.

Con todo ello, la polémica cuestión de establecer los límites en torno a lo que deba quedar oculto, se reconduce a la valoración y apreciación de la gravedad y relevancia de esos otros intereses o de las circunstancias que aconsejen el decaimiento del derecho fundamental, cuestión esta siempre

${ }^{23}$ En la Caso Fressoz y Roire vs. Francia, recurso núm. 29183/95, Sentencia del TEDH de 21 de enero de 1999 se pone de relieve que la conducta de los informadores que publican documentos con datos fiscales proporcionados por funcionarios violando su deber de reserva (es decir, de manera ilícita) no constituye per se un ejercicio ilegítimo del derecho a la información, de manera que la licitud o no de su conducta ha de valorarse teniendo en cuenta otros criterios como, por ejemplo, el interés público de la noticia, su veracidad, la posibilidad de obtener esa información por otros medios, etc., sin que deban asumir responsabilidad alguna por no identificar a quienes les hubieran filtrado esos documentos (con independencia de la eventual responsabilidad de quienes los hubieran filtrado). En la Craxi II vs. Italia, recurso núm. 25337/94, Sentencia del TEDH de 17 de julio de 2003, en relación con la publicación de datos filtrados que pueden lesionar la vida privada de un tercero (como en el caso Fressoz y Roire vs. Francia) el Tribunal afirma que el Estado tiene, al menos, la obligación de iniciar una investigación para determinar las eventuales responsabilidades de los informantes. El juez Zagrebelsky, en su opinión disidente, pone de manifiesto que esta obligación del Estado puede ser imposible jurídicamente si, al mismo tiempo, hay que proteger el derecho al secreto profesional de los periodistas.

${ }^{24}$ Otero González, M. ${ }^{\text {a }}$ P., Justicia y secreto profesional, Centro de Estudios Ramón Areces, Madrid, 2001, pp. 93 y 94. 
difícil de apreciar y ponderar, que ha de efectuarse en cada caso concreto, y con criterio restrictivo.

Cuestión diferente es la relativa a la participación concreta del informador en el acto de revelación (lo que nos remite al problema de la obtención ilícita de información) pero esta es también objeto de investigación por el órgano judicial.

Las expuestas son, sin duda, algunas de las circunstancias que aconsejan una regulación legal de este derecho fundamental que venga a paliar la inseguridad jurídica de los profesionales y facilite la labor de ponderación de los jueces.

En definitiva, el «caso Tellería» refleja el nuevo compás de espera a la llegada de (en palabras de Tomás de la Quadra ${ }^{25}$ ) este «Godot constitucional» que, utilizando la «fórmula choque» del Tribunal Europeo de Derechos Humanos, constituye la "piedra angular de la libertad de prensa» y contribuye a crear para el profesional un amplio espacio de libertad para administrar, como es evidente, la información, pero también el silencio.

Este espacio de libertad no significa inmunidad, y por ello encuentra su correlato en la debida responsabilidad en el ejercicio profesional, para que la libertad de prensa pueda cumplir, legítima y eficazmente, la función de garantía de la democracia a la que está llamada.

\section{EL DESARROLLO DEL SECRETO PROFESIONAL DE LOS PERIODISTAS EN LA JURISPRUDENCIA DEL TRIBUNAL EUROPEO DE DERECHOS HUMANOS}

Si bien es cierto que no se puede afirmar que el secreto profesional de los periodistas carezca en España de regulación jurídica (habida cuenta de su previsión constitucional expresa) no es menos cierto que la sola mención no es suficiente para delimitarlo. La ausencia de regulación legal (a pesar de los reiterados intentos) contribuye a alentar la inseguridad jurídica cuando se trata de aplicarlo al caso concreto, sobre todo, si tenemos en cuenta que la mayor parte de las veces este derecho se presenta en conflicto con otros derechos.

Los amplios márgenes de incertidumbre que el vacío legal deja en relación con esta institución, difícilmente se pueden llenar por referencia a otras figuras anejas o en virtud de los antecedentes reguladores, por varias razones. En primer lugar, por la singularidad del secreto profesional de los informadores frente a otros secretos profesionales que sí tienen entre sí una configuración y un fundamento parejos; en segundo lugar, porque el secreto profesional existe con carácter inequívocamente jurídico y, como derecho, solo desde

25 DE La Quadra Salcedo, T., «La cláusula de conciencia, un Godot constitucional», $R E D C$, núm. 22 y $23,1988$. 
la Constitución española de 1978; en tercer lugar, el precedente más extendido es el de su configuración integrando las obligaciones deontológicas de la profesión, construcción que dista de la configuración jurídica y aún más, en muchos casos, contribuye a oscurecer esta última.

Por todo ello, aunque su reconocimiento constitucional expreso supuso en su momento un logro evidente, esto no es suficiente para garantizar su correcto ejercicio. Por ello es destacable la labor del TEDH profundizando en esta figura consagrando este derecho primero, y definiéndolo después, habida cuenta también del heterogéneo marco normativo europeo.

El reconocimiento del derecho de los periodistas a mantener la reserva de sus fuentes ya se produjo en una jurisprudencia temprana del TEDH, que lo dedujo del artículo 10 del Convenio, habida cuenta de la intensa vinculación de esta figura con la libertad de información (por todos, casos Goodwin c. Reino Unido, de 23 de marzo de 1996, Fressoz y Roire c. Francia, de 21 de enero de 1999).

En la reciente sentencia Nagla $c$. Latvia, de 16 de julio de $2013^{26}$, el Tribunal incorpora el concepto de secreto profesional de los periodistas recogido en la $R$ (2000) 7, del Consejo de Europa que contiene una definición amplia de «fuente periodística» que incluye a «toda persona que proporciona informaciones a un periodista», así como la «información identificativa de una fuente», y lo extiende incluso a «la parte no publicada de la información proporcionada por un periodista» así como sus notas y apuntes. La sentencia citada también pone de manifiesto el efecto disuasorio que para las fuentes se derivaría en el caso de que los periodistas colaborasen en la identificación de fuentes anónimas.

Otra cuestión relevante es la de precisar el objeto del secreto profesional. Esencialmente el objeto del secreto es mantener el anonimato de las fuentes informativas, pero queda por determinar si esta facultad se limita solo a la protección puramente nominal de la identidad del informante, o si desde el punto de vista material se extiende para proteger todo aquel material que pueda indiciariamente identificarla o los lugares en que se depositan.

Como señala Azurmendi, «este de la ampliación del objeto del secreto profesional no es un asunto menor pues la legislación que no lo contempla, está siendo, de hecho, restrictiva en las garantías de la profesión periodística» y añade que «como con acierto señala la ley austriaca de 1981, no es lógico que a renglón seguido, por omisión, se deje abierta una puerta para su vulneración $»^{27}$.

${ }^{26}$ Cfr. Caso Nagla c. Latvia, recurso núm. 73469/10, Sentencia del TEDH de 16 de julio de 2013, §81.

27 Azurmendi Adarraga, A., «El secreto profesional», en MAllén, I., CorredoIRA y Alfonso, L. (coords.), Derecho de la información, Bel Ariel, Barcelona, 2003, pp. 315 y 316 . 
Si en el asunto Fressoz y Roire c Francia el Tribunal no entró a pronunciarse acerca de si el secreto profesional amplía su protección a todo el material utilizado o creado por el periodista que indiciariamente pudiera conducir a la identificación de la fuente (como notas, grabaciones, documentos, etc.) lo cierto es que en otras resoluciones ha ampliado considerablemente el objeto en el sentido indicado (como por ejemplo en SSTEDH Roemen y Schmit c. Luxemburgo, de 25 de febrero de 2003, Ernst y otros c. Bélgica, de 15 de julio de 2003, Tillack c. Bélgica, de 27 de noviembre de 2007, Sanoma II c. Países Bajos, de 14 de septiembre de 2010, o más recientemente, Nagla $c$. Latvia, de 16 de julio de 2013, que se refiere expresamente a los ordenadores portátiles, memorias externas, tarjetas de memoria o discos duros, en definitiva, los nuevos soportes de información y almacenaje).

En estas resoluciones no solo se consideran dentro del ámbito de protección del secreto profesional los materiales sino, aún más, los lugares de trabajo, la residencia, o incluso los vehículos y unidades móviles de los informadores, apreciando injerencia en los derechos garantizados por el art. 10, apartado 1 del Convenio cuando los registros domiciliarios y de los locales profesionales fueron indiscriminados, o no gozaron de las debidas garantías también para el secreto profesional.

Abundando en esta ampliación, se matiza incluso que la ausencia de resultado de dichas diligencias por no haber podido obtener la información buscada no le priva de objeto ni sana la conducta. Recientemente, en la ya citada sentencia Nagla c. Latvia, de 16 de julio de 2013 (como anteriormente hiciera en Röemen y Schmit c. Luxemburgo, 2003) el Tribunal pone de manifiesto que los registros o intervenciones de la policía y aún los ordenados por la autoridad judicial, cuando van dirigidos a desvelar la identidad de las fuentes «constituyen un acto más grave que el propio requerimiento judicial al periodista para que lo haga». Por ello señala que las limitaciones a la confidencialidad de las fuentes periodísticas reclaman el mayor cuidado en el escrutinio por el Tribunal acerca de la consideración de si las razones que motivan las diligencias de registro son «razonables» y «suficientes» para justificar la limitación del derecho al secreto profesional.

Respecto de los límites del secreto profesional, es decir, los supuestos en los que no opera, en el caso examinado se hace especial énfasis en la eventual eficacia del secreto en el supuesto de las filtraciones periodísticas. Particularmente se refiere y adopta el criterio de la STEDH Stoll c. Suiza I, de 25 de abril de 2006.

Esta sentencia (y la posterior STEDH Stoll c. Suiza II, de 10 de diciembre de 2007) abordan la cuestión de la legitimidad de la publicación de diversos artículos periodísticos elaborados sobre la base de un documento diplomático interno clasificado como «reservado», transcribiendo parcialmente algunos de sus contenidos. En este caso no queda acreditado que el periodista haya tenido ninguna intervención en la filtración. 
En realidad estas sentencias no se detienen en la cuestión del secreto profesional. Lo relevante aquí no es que el periodista no revele quién filtró la información, sino que esa información tenía carácter secreto o «reservado». Sobre este dato, el Tribunal aporta unos interesantes criterios que, a la postre, pueden servir en la práctica para corregir en parte el fenómeno de la filtración.

Resulta también de interés la referencia a que el hecho de que la divulgación de la información sobre una materia esté legalmente prohibida y que dicha limitación sea conforme con el art. 10-2 CEDH (que prevé como límite al derecho a la información la protección de la seguridad nacional) no implica que el periodista esté obligado a identificar al autor de la filtración, «pues no se pueden confundir los límites a la libertad de información con los límites al secreto profesional de los periodistas». Esta resolución recuerda también que «corresponde en primer lugar a los Estados organizar sus servicios y formar a sus agentes de manera que ningún dato confidencial o secreto se divulgue».

En relación con el requisito de la veracidad, resulta de interés la doctrina del Tribunal adoptada en la sentencia Cumpânâ y Mazâré, de 17 de diciembre de 2004 (aunque en este caso no se plantea la cuestión del secreto profesional de los periodistas más que de modo colateral, y de forma puntual) y después reiterado en la STEDH Stângu y Scutelnicu c. Rumania, de 31 de enero de 2006 (si bien, en esta ocasión, sí hubo alegación expresa del secreto profesional como causa de no poder probar totalmente la veracidad de los hechos).

En Cumpânâ y Mazâré se aborda un supuesto de condena a dos periodistas por delitos de injuria y calumnia por la emisión de expresiones críticas presuntamente ofensivas, así como por la atribución de hechos fundada (entre otras fuentes) en un informe del Tribunal de Cuentas que se hizo público un mes después del artículo periodístico.

Aunque los periodistas nunca alegaron expresamente el secreto profesional en relación con la prueba de la veracidad de sus afirmaciones, sí manifestaron ante la Corte de Estrasburgo que si no proporcionaron el informe del Tribunal de Cuentas como base de la acusación de estafa que realizaban en su artículo periodístico, ello se debió a «su deseo de no perjudicar a sus fuentes».

En el caso El Tribunal reitera los argumentos anteriormente utilizados en Cumpânâ y Mazâré acerca del importante papel que la prensa juega en una sociedad democrática, y recuerda que no se pueden traspasar ciertos límites, como los referentes a la protección de la reputación y los derechos de los demás, así como a la necesidad de impedir la divulgación de informaciones confidenciales $^{28}$. También, como en dicha sentencia, reitera que el deber de

${ }^{28}$ Cfr. STEDH Stângu y Scutelnicu c. Rumania, de 31 de enero de 2006, § 4. 
los demandantes de proporcionar una base factual sólida para las acusaciones enjuiciadas no implica la obligación de desvelar los nombres de las personas que habían facilitado dichas informaciones en las que se fundaban para redactar su artículo ${ }^{29}$.

Ciertamente los criterios sentados por el Tribunal no se limitan a los señalados sino que, en su ya numerosa jurisprudencia, ha venido adoptando soluciones en función de la variada casuística que se le ha presentado. Sin duda, la más rica se refiere a los criterios de ponderación en los casos en que el secreto profesional colisiona con otros intereses relevantes. No obstante, la heterogeneidad de criterios de los diferentes ordenamientos nacionales, sobre todo cuando se trata de la protección de información pública, dificulta la labor interpretativa y en último extremo, la posibilidad de su adopción de manera uniforme.

\section{BIBLIOGRAFÍA}

CARRILlO, M., La cláusula de conciencia y el secreto profesional de los periodistas, Generalitat de Catalunya, Centre d'Investigació de la Comunicació, Cuadernos Civitas, Civitas, Madrid, 1993.

FERnÁNDEZ-Miranda CAMPOAMOR, A., El secreto profesional de los informadores, Tecnos, Madrid, 1990.

LazCano BRótons, I., El secreto profesional en el periodismo, Lete Argitaletxea, Bilbao, 2007.

Moretón Toquero, A., El secreto profesional de los periodistas: de deber ético a Derecho fundamental, Centro de Estudios Políticos y Constitucionales, Madrid, 2012.

Otero GonzÁlez, M. ${ }^{\text {a }}$., Justicia y secreto profesional, Centro de Estudios Ramón Areces, Madrid, 2001.

VILlanueVA, E., El secreto profesional del periodista. Concepto y regulación jurídica en el mundo, Fragua, Madrid, 1998.

TITLE: The protection of information sources: integration of Spanish model with ECHR jurisprudence.

RESUMEN: La protección de las fuentes es un elemento esencial en el ejercicio del periodismo, al servicio del flujo informativo. Este instrumento de protección ha recibido durante mucho tiempo una atención escasa desde el punto de vista jurídico y, sin embargo, con frecuencia los propios medios visibilizan episodios de alegación o controversia en relación con sus elementos constitutivos. En su momento, España fue pionera constitucionalizándolo como derecho fundamental en el art. 20.1 d) CE. Sin embar-

${ }^{29}$ Cfr. STEDH Stângu y Scutelnicu c. Rumania, de 31 de enero de 2006, § 52. 
go, la ausencia del desarrollo legal previsto en la Constitución lo mantiene como una cuestión abierta en nuestro país.

Este vacio normativo, en la práctica se ha venido a llenar recurriendo a los criterios adoptados por el Tribunal Europeo de Derechos Humanos en su jurisprudencia sobre el art. $10 \mathrm{CEDH}$, que en la última década ha sido especialmente abundante y ha venido a actualizar y definir los elementos fundamentales de esta figura.

PALABRAS CLAVE: secreto profesional, fuentes informativas, libertad de información, derechos fundamentales, transparencia, estatuto profesional.

ABSTRACT: The protection of sources is an essential element in the practice of journalism in the service of information flow. This instrument of protection has long been scant attention from the legal point of view; however, the media themselves often make visible episodes of claim or controversy regarding its components. At the time, Spain was a pioneer by including it as a fundamental right in Art. 20.1 d) EC. However, the absence of legal development under the Constitution as it remains an open question in our country. This regulatory vacuum has filled in practice using the criteria adopted by the European Court of Human Rights in its case law on Art. 10 ECHR, which in the last decade has been particularly generous and has come to update and define the key elements of this figure.

KEYWORDS: reporter's privilege, information sources, freedom of the press, fundamental rights, transparency, journalist's statute. 